\title{
THE PROFILES OF METACOGNITIVE READING STRATEGIES OF SUCCESSFUL AND UNSUCCESSFUL EFL LEARNERS OF SENIOR HIGH SCHOOL
}

\author{
Muhammad Reffyal ${ }^{1}$, Abidin Pammu $^{2}$, Sukmawaty ${ }^{3}$ \\ ${ }^{123}$ English Language Study Program, Faculty of Cultural Sciences, \\ Hasanuddin University, Makassar \\ reffyalmuhammad@gmail.com \\ abidinpammu60@yahoo.com \\ sukmamumu@yahoo.com
}

\begin{abstract}
The ability to read in English as a foreign language is very important for senior high school because it will affect their productive skills such as writing and speaking. The objective of this research was to present the profiles of metacognitive reading strategies of successful and unsuccessful EFL learners of high school at SMA Negeri 1 Pamboang. The address of reading strategies is expected to provide useful information both for students and teachers secondary school. At least, the information about strategies can improve the quality of education especially in teaching reading as a core subject. The current study reports an investigation of EFL learners profiles of metacognitive reading strategies in Indonesian context. This exploratory paradigm was an attempt to reveal what level of metacognitive awareness of both successful and unsuccessful learners at the senior high school level. The study was carried out at SMA Negeri 1 Pamboang, Majene Regency and employed quantitative and qualitative methods. Using purposive sampling method, seventy-two (72) EFL learners filled in the MARSI questionnaire (Metacognitive Awareness Reading Strategy Inventory) by Mokhtari \& Reichard (2002) to deal with the metacognitive part. 20 samples from seventy-two participants were selected to participate in interview session. The former employed statistical tool (SPSS 22) to reveal the level of learners' metacognitive awareness. The statistical analysis indicated high level of metacognitive of awareness in all sub-scales (Global Strategy, $\mathrm{M}=3.59, \mathrm{SD}=0.56$, Support Strategy, $\mathrm{M}=3.51, \mathrm{SD}=0.77$, Problem Solving Strategy, $M=3.77, \mathrm{SD}=0.65$ ) for the successful group. The unsuccessful group, on the other hand, indicated medium level on both Global and Support Strategy $(\mathrm{M}=3.16, \mathrm{SD}=0.60$, $\mathrm{M}=3.06, \mathrm{SD}=0.49)$ with the exception of Problem Solving Strategy with a high level of awareness $(\mathrm{M}=3.58, \mathrm{SD}=0.55)$. Interviews showed that many students, especially unsuccessful learners, have a clear purpose when reading but when they did not understand they choose to discuss with friends. This finding warranted the need for the design of strategy training with the focus on strategy consolidation to make these learners employ these existing strategies in more productive and efficient manner.
\end{abstract}

Keywords: Metacognitive, reading strategies, successful and unsuccessful learners

\section{INTRODUCTION}

Reading is one of four language skills needed by students who learn English as a foreign language in Indonesian tertiary education. The ability to read in English as a foreign language is very important for senior high school because it will affect their productive skills such as writing and speaking. As Brown (2001), stated that reading activities will provide students with models to produce language (in written or spoken text). In the context of SMA Negeri 1 Pamboang, where the research was conducted, reading activities have still been largely ignored. Students seem to have limited ability to interpret the information from the texts, think critically and use context clues to find meaning. Reading comprehension instruction in many classrooms focused on teachergenerated questions or is based on textbook instruction, which measures 


\section{7 | JURNAL ILMU BUDAYA}

Volume 6, Nomor 1, Juni 2018

comprehension of a specific text rather than metacognitive strategies for comprehending texts. The effort for improving the academic reading in the country is triggered by the present demands that those with high level of literacy skills in English often easily gain the job advertised (Pammu et al., 2012). To improve reading skills, strategy is needed to make reading activities more effective.

According to Zhang et al (2008), using reading strategies indicates how readers approach tasks and what they do to construct meaning from the texts and what they do when comprehension breaks down. Without a strategy, reading will not be effective or will not match the expected results. Because of that the researcher is very interested in the research of reading strategies and researchers also continue to develop the reading strategies to achieve maximum results. Secondly, Maasum \& Maarof (2012), carried out a research entitled "Empowering ESL Readers with Metacognitive Reading Strategies". They carried out a research on the metacognitive reading strategies applied by a group of EFL undergraduate students when reading academic texts as a public university. Onovughe \& Hannah (2011), argued that certain strategies are used by students to correct failure of comprehension, including slow and careful reading, rereading controls reading levels, pausing to reflect on reading, and reading the text aloud.

The importance of metacognitive reading strategies is apparent in the problem solving process of obtaining meaning from the text. Anderson (2005), states that metacognition is central to the understanding of good language learner. Metacognition is central to productive learning because it includes preparing and planning for learning, evaluation of learning, selection, and use of strategies monitoring of learning.
Some researchers have been conducted about metacognitive reading strategies. Othman et al (2014), carried out a research entitled "The Effects of Metacognitive Strategy in Reading Expository Text". This study evaluated the performance of student achievement during lesson of comprehension using metacognitive strategy and examined the effects of the strategy used in reading and understanding expository text lessons. Furthermore, Habibian (2015), conducted a study entitled "The Impact of Training Metacognitive Strategies on Reading Comprehension among ESL Learners". The study investigated the impact of training metacognitive strategies in reading comprehension and was conducted among students from University Putra Malaysia.

Moreover, Sohbani (2013), did a research on "Metacognitive Reading Strategies Use by Yemeni EFL Undergraduate Students". The research was aimed to explore the reading strategies use of Yemeni university learners and to determine whether females and males were significantly varied in their utilization of reading strategies. The final important research is by Fitrisia et al (2015), who researched on Metacognitive Awareness of Reading Strategies entitled 'Investigating Metacognitive Awareness of Reading Strategies to Strengthen Students' Performance in Reading Comprehension". In this research addressed the investigation of profiles successful and unsuccessful learners, the empowerment, the effects of metacognitive reading strategies, and the application of training on it, the comparison of metacognitive strategies with sex and physical location.

From the previous researches on Metacognitive Reading Strategies, most researches were applied to ESL and EFL Learners. Another research was in medical junior college students. This research addressed the investigation, the empowerment, the effects of metacognitive reading strategies, and the 
138 | JURNAL ILMU BUDAYA

Volume 6, Nomor 1, Juni 2018

application of training on it, the comparison of metacognitive strategies with sex and physical location.

As a result, little has been reported on the profile of metacognitive strategies especially in reading strategies for the grade two of secondary level education that is the senior high school students, especially in the context of West Sulawesi is almost nonexistent. That's why I did this research to find out the metacognitive reading strategies of successful and unsuccessful EFL learners at one school in West Sulawesi. Furthermore, there is little emphasizing on the use of MARSI questionnaire to find out the metacognitive reading strategies which are to make it more specific that are the learners are put into two categorizations: successful and unsuccessful learners. So that, this study addresses the profile of the metacognitive reading strategies for both learners: successful and unsuccessful.

\section{MATERIAL AND METHOD}

This part explains about the methodology of the research in specific.

\section{Location and Research Design}

The research took place at SMA Negeri 1 Pamboang, Majene Regency of second grade students. The study employed a quantitative and qualitative research design by using a questionnaire and interview. The profile of metacognitive reading strategies of successful and unsuccessful learners was assessed by applying the Metacognitive Awareness of Reading Strategies Inventory.

\section{Subject}

The total number of students were 76 that divided into two groups. There were 27 students as successful learners and 45 were treated as unsuccessful learners. Purposive sampling technique was used by the researcher to select the subject of the study.

\section{Data Collection}

As the successful and unsuccessful learners were identified, the researcher sketched the number of questionnaire to be delivered to the samples. As many as 72 questionnaires were distributed to students, 27 for successful learners and 45 for unsuccessful learners. The investigator provided about 30 minutes to complete the questionnaire. Investigators also monitored the process of filling in the questionnaire to see if there were some problems during the process. And retrieved supporting data through interviews after filling out the questionnaire.

\section{Data Analys is}

The quantitative measure involved in this study was based on descriptive statistics. The gathered data were analyzed by implementing the Statistical Packages for the Social Sciences (SPSS) version 22 for Windows. Descriptive statistics (frequencies, means, and standard deviations) were calculated for summarizing demographic information and describing students' reading strategy. The main type of data analysis employed Likert-Scale 5 that ranged from 1 to 5 with a description from never/almost never to always. The high scale implied strong tendency of the subject to be categorized as having high level of metacognitive awareness within each of the three group categories.

Three key averages were used, such as 3.5 or higher as HIGH, 2.5 to 3.4 as MEDIUM, 2.4 or lower as LOW. By using microsoft Excel, the data were uploaded into the Statistical Package for the Social Sciences (SPSS) program in order to get mean score and Standard Deviation (SD).

\section{FINDINGS}

A Metacognitive Awareness of Reading Strategy Inventoy (MARSI) has been the primary research instrument adopted for the study for gathering data on learners' metacognitive awareness. The instrument having 30 items measures learners' metacognitive awareness of reading processes. The instrument has three subscales of strategy that include Global Strategy (GLOB) with 13 items, Support Strategy (SUP) with 9 items, and Problem 
139 | JURNAL ILMU BUDAYA

Volume 6, Nomor 1, Juni 2018

Solving Strategy (PROB) with 8 items. The 5 Likert Scale is used to identify the level of awareness and is calculated using SPSS Window 22 which indicates the respondents' overall self-report on their own level of strategy use in the form of mean score and standard deviation (SD).

The overall average indicates how often learners employ certain strategies while reading an academic material. The average for each sub-scale of the inventory shows, which sub-group of strategy (i.e, GLOB, SUP, PROB), gain higher tendency of reading awareness in each proficiency group. This will convey information whether the learners group belongs to LOW category, MEDIUM category, or HIGH in any of the three groups. The higher rate of perceived use of these strategies will depend on various variables that include learners' linguistic competence, their reading ability in English, type of reading materials, range of vocabulary, and the reading purpose. In contrast, a low score on any of the subscale or part of the inventory would imply if these perceived strategies were unlikely not used during the reading process.

\section{Descriptive Findings}

Descriptive results of metacognitive reading strategy of the EFL learners will be presented by using mean score. The mean score is regarded more appropriate in this context rather than the total sum of score because the number of item in each construct is not equal. The total sum of score is frequently used when between construct has the same number of items. In addition, the total sum of score is also used most appropriately in scoring and interpreting the test results, such as Language Testing and IQ test. However, the perception of a phenomenon, such as reading strategy use by the EFL learners, mean score are then the most appropriate instrument to be used in reporting and interpreting the findings.
In this section, the mean score for each strategy is analyzed by grouping the items that are under the same construct together and sought the grand mean score. For instance, to obtain the mean score for the construct of 'metacognitive strategy, item 1-5 from the respondents report are grouped together to find the mean score. The same applies for other constructs. The higher the mean score the higher the tendency of such perceived strategy use. The range of score obtained would also imply the emergence variability of strategy use although certain strategies do not seem to be in use by certain group of students in the investigation.

Descriptive Findings of Proficient and Less Proficient Learners

This part presents the sum of the mean score (M), standard deviation (SD) and description that reflect the reported use of strategy in reading. The higher the mean score the higher the tendency of the reported use of strategy. The following tables are the summary of the total mean score and standard deviation in the three sub-scales of the inventory (Global Strategy, Support Strategy, and Problem Solving Strategy) in both groups. The details of the mean score, standard deviation of level of metacognitive awareness of both groups is in the next description.

The findings showed that successful learners group outperforms the unsuccessful learners group in terms of three sub-scales of metacognitive strategy. All sub-scales exhibit high level of awareness implying that this group was highly aware of making use of those strategies when reading textual materials. These three types of strategies (Global Strategies, Support Strategies, and Problem-Solving) interact with each other in terms of metacognitive strategies and have an important influence on text comprehension on these learners. The unsuccessful group, on the other hand, scored lower in two sub-scales (GLOB, 
SUP) who yielded at medium level of awareness $\quad(\mathrm{M}=3.16, \quad \mathrm{SD}=0.60 \quad$ and $\mathrm{M}=3.06, \quad \mathrm{SD}=0.49$ ). $\quad$ They performed variability in the level of metacognition where problem solving strategy yielded at high level of awareness implying that these learners employed a set of strategy oriented when text generates problems.

The mean comparison between successful and unsuccessful group of their metacognitive awareness is presented in the following figure. The figure illustrates clearly the level of metacognitive awareness in the three sub-categories of MARSI inventory. The successful group exhibited different level of metacognitive awareness from the unsuccessful group. This group outperforms the unsuccessful group in the three sub-scales of metacognitive reading strategy with the overall mean score (3.62 to 3.27). This implies that the successful group is better aware of global analysis of text and aware of the use of outside reference material as well as range of reading resolutions when text generates difficulties.

\section{DISCUSSION}

This research found that the successful learners' awareness over the three sub categories of reading strategies in the inventory shows significant degree of awareness with the mean score indicated Global Strategy $(\mathrm{M}=3.59, \quad \mathrm{SD}=0.20)$, Support Strategy $(\mathrm{M}=3.51), \quad \mathrm{SD}=0.23)$, Problem Solving Strategy $(\mathrm{M}=3.76$, $\mathrm{SD}=0.13$ ). The three sub-categories of reading strategies belong to the high level that implies significant degree of awareness in a wide range of reading strategies. Some factors that may affect the level of comprehension despite high level of awareness may include L1 interference, range of vocabulary acquisition, reading experience, and linguistic competence. This would confirm that several factors that account for the needs of reading strategies for the EFL context should be considered for the material design especially in the teaching of reading at high school level. This part is an address for each of the strategy sub-group in detail in subsequent order beginning with Global Strategy, Support Strategy and Problem Solving Strategy.

The awareness of the unsuccessful learners has yielded at the high level of mean score and standard deviation on the three sub-scales of MARSI inventory. This medium level of awareness implies that they are not aware of their own reading strategy needs, thinking, and understanding. These strategies provide the support mechanisms aimed at sustaining responses to reading. These three types of strategies (Global, ProblemSolving, and Support Strategies) interact with each other and have an important influence on text comprehension.Tthis awareness proves that the learners in the Indonesian context, metacognition plays minor roles in the problem solving tasks of reading in a foreign language with the presence of enormous linguistic problems. It seems to be little about the significance of level of learners' awareness and their reading performance. In other words, the awareness is not sufficient to make the learners to get in planning, organizing, controlling as well as evaluating their reading process.

The learners' awareness over the three sub categories of reading strategies in the inventory shows awareness with the mean score indicated Global Strategy $(\mathrm{M}=3.16$, $\mathrm{SD}=0.15)$, Support Strategy $(\mathrm{M}=3.12)$, $\mathrm{SD}=0.38)$, Problem Solving Strategy $(\mathrm{M}=3.58, \quad \mathrm{SD}=0.33)$. The two subcategories of reading strategies belong to the medium level that implies the medium of awareness except problem solving strategy in a wide range of reading strategies. Some factors that may affect the level of comprehension despite high level of awareness may include L1 interference, range of vocabulary acquisition, reading experience, and linguistic competence. EFL context should be considered for the material design especially in the teaching 


\section{1 | JURNAL ILMU BUDAYA}

Volume 6, Nomor 1, Juni 2018

of reading at high school level. This is a sub-group in detail in subsequent order beginning with Global Strategy, Support Strategy and Problem Solving Strategy.

\section{CONCLUSION}

This study has presented empirical evidence reflecting learners' metacognitive use on their reading strategies of different proficiency level, the successful and unsuccessful learners. The results showed a positive linear relationship between the two variables indicating that high text achievers were more metacognitively aware of reading strategies than those in the lower level while attempting to comprehend a text. A further recommendation for classroom practices is a need for teachers to be highly creative in finding ways to promote the development of effective strategy use by creating group discussion or using peer feedback in interactive classroom environment, teaching reading strategies through teachers' explicit verbalization using think-aloud technique skills within classroom instruction for EFL learners need to include techniques and methodologies that concern extensive reading. Finally, teachers should be able to make their learners able to reflect, analyze and refine ideas and critically think what they are reading. In this way, learners need to approach academic text in more holistic way and avoid their habit of paragraph-byparagraph processing of the text. It is essential to make learners aware of the importance of reflecting the information in the text to enable them to understand the information.

\section{BIBLIOGRAPHY}

Anderson N. (2005). L2 Strategy Research. In E. Hinkel (Ed.), Handbook of Research in Second Language Teaching and Learning (pp.757772). Mahwah, NJ: Lawrence Erlbaum Associates.

Brown H.D. (2001). Teaching by Principles. San Francisco: Addison Wesley Longman.

Fitrisia D., Kok-Eng Tan., \& Yunisrina Q. Y. (2015). Investigating

Metacognitive Awareness of Reading Strategies to Strengthen Students' Performance in Reading Comprehension. Asia Pacific Journal of Educators and Education, Vol. 30, 15-30.

Habibian M. (2015). The Impact of Training Metacognitive Strategies on Reading Comprehension among ESL Learner's. Journal of Education and Practice vol 6, No. 28.

Maasum T.N.R.T.M. \& Maarof N. (2012). Empowering ESL Readers with Metacognitive Reading Strategies. Procedia - Social and Behavioral Sciences 69, $1250-1258$.

Othman Y., Mahamud Z., \& Jaidi N. (2014). The Effects of Metacognitive Strategy in Reading Expository Text. International Education Studies; Vol. 7, No. 13; ISSN 1913-9020 E-ISSN 19139039. Published by Canadian Center of Science and Education 102.

Onovughe G. \& Hannah A. (2011). Assessing ESL students' awareness and application of metacognitive strategies in comprehending academic materials. Journal of Emerging Trends in Educational Research and Policy Studies, 2(5), 343-346.

Pammu A., Amir Z., \& Rizan T.N. (2012). Metacognitive Awareness in Reading Strategies: A case 


\section{2 | JURNAL ILMU BUDAYA}

Volume 6, Nomor 1, Juni 2018

Study of Proficient Learners at Hasanuddin University, Indonesia. ICOSH2012. UKM. Bangi.

Sohbani Y.A. (2013). Metacognitive Reading Strategies Use by Yemeni EFL Undergraduate University Students. Frontiers of Language and Teaching Volume 4121.

Zhang L.J., Gu P.Y., \& Hu G. (2008). A Cognitive Perspective on Singaporean Primary School Pupils' Use of Reading Strategies in Learning to Read in English. British Journal of Educational Psychology no. 78. 